\title{
EMERGENCY RESPONSE CAPABILITY ASSESSMENT OF EMERGENCY SUPPLY CHAIN COORDINATION MECHANISM BASED ON HESITANT FUZZY INFORMATION
}

\author{
Chen, Y.-X.* \& Song, Y. \\ School of Economics and Management, Harbin Engineering University, Harbin 150001, China \\ and \\ Institute of Disaster and Crisis Management, Harbin Engineering University, Harbin 150001, China \\ E-Mail: chenyxdingdang@ @rbeu.edu.cn ("Corresponding author)
}

\begin{abstract}
In recent years, as global economy is intertwined, the competition among enterprises is epitomized by the supply chain. Owing to its vulnerability, once there are emergencies, huge losses would take its toll. Therefore, it is significant to assess the emergency response capability of the emergency supply chain coordination mechanism. However, during the assessment, subjectivity of experts may make things complicated and cause a lack of information and fuzziness. Thus, this paper proposes a TOPSIS METHOD based on hesitant fuzzy information to address the abovementioned issue. Numerical analysis proves that the method is efficient and accurate.

(Received, processed and accepted by the Chinese Representative Office.)
\end{abstract}

Key Words: Emergency Supply Chain Coordination Mechanism, Emergency Response Capability Assessment, Hesitant Fuzzy Information, Assessment System

\section{INTRODUCTION}

Strategies such as "Zero Inventory" and "Agile Production" retrench the supply chain to a great extent. Though these strategies reduce inventory cost and production cost, the supply chain turns out to be more fragile. Internal and external complexity of the supply chain expose the supply chain itself with huge risk of losses, in particular under the emergencies that may lead the supply chain to interrupt or collapse.

Unexpected risks of the supply chain refer to that the original plan cannot keep operation due to the variation of the environment. What is trigger is that such risks cannot be predicted. Once happened, the losses would be huge. We call the relevant management as Emergency Management [1]. Lei studied the relationship between the security and the cost [2]. $\mathrm{He}$ constructed a linear regression model and a function expression for emergencies by analysing the pay cost.

Zhu developed an emergency management mechanism model [3]. Li used AHP and fuzziness assessment method to assess the supply chain emergency response capability according to assessment indicators which he built [4]. Xiao and $\mathrm{Yu}$ studied the management strategy under supply disturbances [5]. They expressed the supply disturbances as Markov process and discussed the retailer's market strategy under duopoly market. Tomlin and Wang analysed the emergency management strategies of shorter life cycle product $[6,7]$. They studied the measurement and selection in preventive measures and emergency measures. They also supposed that decision makers were risk neutral. In their study, the target function was to have the minimum cost or the maximum profits.

There are no short of scholars studying strategies for coping with emergencies in order to bring the losses to the minimum. The most common way is to introduce the coordination mechanism to adjust behaviours and strategies of enterprises. Deng studied the supply chain emergency aid coordination [8]. This paper thought that aid coordination among partnerships 
may not only enhance the stability of the supply chain, but also increased its performance. At the same time, the author adopted $\mathrm{CVaR}$ to describe the differences between risk preferences and control the losses as a result.

Nosoohi and Nookabadi studied the customer-oriented coordination contract system [9]. Though the contracts, producers closed their retailers whom they shared profits or losses. As a result, producers were able to obtain the best orders and customers were granted with the best price. Luo and Zhang introduced trading credit as a new sort of contract coordination mechanism under asymmetry information [10].

Even though a lot work has been done, there remains a piece of blank in the area of emergency response capability assessment under the supply chain coordination mechanism. With capability assessment, coordination mechanism and coordination strategy can be assessed and improved to enhance anti-risk capability.

TOPSIS (technique for order preference by similarity to an ideal) was a multi-attribute decision making method proposed by Hwang and Yoon in 1981 [11]. This method works out by calculating the distance of the alternative to the Positive ideal solution (PIS) and that to the Negative ideal solution (NIS), ranking them and finding out the solution that is nearest to PIS and furthest to NIS.

TOPSIS is widely accepted in many fields, such as treasury fund [12], freight [13], market assessment [14], etc. People often hesitate when making a decision. During the assessment, subjectivity of experts may make things complicated and cause a lack of information and fuzziness. The fuzzy set proposed by Zadeh was applied to uncertainty assessment and expanded to 2-tuple fuzzy sets [15] and intuitionistic fuzzy sets (IFS) [16].

Torra and Narukawa introduced hesitant fuzzy set $[17,18]$ in which the membership of the element is expressed by a value between 0 and 1. Experts' preference is expressed in the way of hesitant fuzzy number and the attitude towards risks is also considered, making the decision result more reliable.

In this paper, we first proposed an emergency response capability assessment system under the emergency supply chain coordination mechanism according to design principles and based on domestic and foreign-related researches. Then, aimed at subjectivity of experts' preference and existing TOPSIS METHOD, we introduced a generalized hesitant fuzzy distance to TOPSIS and addressed the ranking by proposing a new closeness coefficient. Here comes the new assessment method, namely, TOPSIS based on fuzzy hesitation information.

The first section is the introduction, focusing on the research status of supply chain coordination management and emergency response capability as well as the development of TOPSIS METHOD. The second section is emergency response capability assessment system under the emergency supply chain coordination mechanism. It gave an introduction of the supply chain coordination mechanism and supply chain emergency and proposed an emergency response capability assessment system under the emergency supply chain coordination mechanism in accordance with relevant design principles and research results home and abroad. The third section is based on fuzzy hesitation information of the assessment framework. In this section, we introduced hesitant fuzziness, proposed an improved TOPSIS METHOD and established a framework. The fourth section is numerical experiments and simulation. We first assessed the emergency response capability under the emergency supply chain coordination mechanism based on TOPSIS METHOD and obtained the distance of the alternative to the positive and negative ideal solutions. We also studied the effect of changing parameters. Finally, the experiment proved that such method is robust with good validity and accuracy. 


\section{EMERGENCY RESPONSE CAPABILITY ASSESSMENT SYSTEM UNDER THE EMERGENCY SUPPLY CHAIN COORDINATION MECHANISM}

\subsection{Supply chain coordination mechanism}

\subsubsection{Definition of supply chain coordination}

Supply chain is a complete chain which consists of many nodes. It better fits into the description that "cooperation and competition are twins". On each node, enterprises compete with each other. They are entitled with different rights of decision-making. As enterprises are profit-oriented, conflict may rise. These lower down the efficiency or even cause a series of contradictions like increasing inventory cost and production cost, trust breakdown or degraded business. What's worse, the supply chain may collapse. Therefore, it is significant to coordinate the supply chain for the purpose of integrated management of all enterprises and increasing efficiency.

Supply chain coordination ensures the flow of logistics, information and capital so as to reduce the losses that are brought by inconsistent targets of enterprises. By adjusting the cooperation, enterprises may prefer decisions that are beneficial to the whole supply chain to constrain individual behaviours and increase the benefits for all.

\subsubsection{Classification and method of supply chain coordination}

Supply chain coordination is hotpot in management. There are three dominant research areas:

(1) Artificial intelligence

Artificial intelligence agent system and supply chain are combined together to get the purpose that supply chain coordination. Supply chain coordination is realized through a few agent and information exchange.

(2) Supply chain contract coordination

By the constraint of the contract, enterprises at each node function coordinately and stay closer to the overall target for a win-win result.

(3) Mathematical optimization

Supply chain coordination is achieved through a series of mathematical optimization. Centralized control of supply chain and establishing strategic partnership relationship are two focuses of supply chain coordination. The former method is to make the supply chain centralized controlled by core enterprises at the cost of harming those at other nodes. The latter method aims at improving the overall performance by cooperation. General framework of supply chain coordination is shown in Fig. 1.

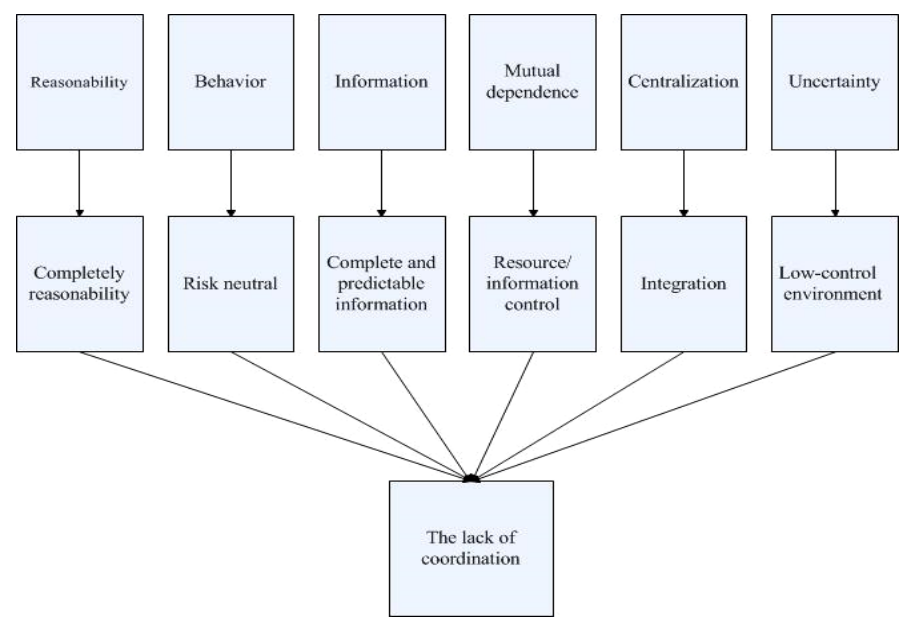

Figure 1: General framework of supply chain coordination research. 


\subsection{Emergencies and emergency management of supply chain}

With the economic globalization and popularization of the information technology, the supply chain obtains a new chance of development. For enterprises, how to reduce the inventory and accelerate the turnover is the key to the modern battle. Many enterprises have set up more agile supply chain and that strategy results in a reduced cost. However, the bad news is that the enterprises at the nodes are more reliant to each other, which makes the supply chain more vulnerable to huge losses. Emergencies of the supply chain have following causes:

(1) Efficiency-oriented rather than effectiveness-oriented. Modern enterprises are switching to "Zero Inventory". The merit of this business model is undeniable in a globalized market. But once there is a demand fluctuation, the weakness of lacking flexibility will be magnified.

(2) Trends in global supply chain. As the current supply chain is operated in the context of globalization, it links more closely with the rest of the world through remote sourcing and global production. Decision makes may give a glance at the purchase cost and the production cost, but they often neglect the overall cost of the supply chain. In the market where the life cycle of the product is short, costs of lead-time, safety stock and scrap often lead to greater risks.

(3) Centralized production and distribution. The modern enterprise factories tend to clump together to form the industrial park. As a result, production costs are significantly reduced, but transportation costs rise as products are transported to the further distance.

(4) Business outsourcing. Multiple powerful companies are integrated to enhance their own strength. However, outsourcing contains huge risks in that once problem appears in some link of the supply chain; the whole one has a higher occurrence of unexpected events.

(5) Demand fluctuation. Fluctuations in demand cause the bullwhip effect and bring demand uncertainty of the supply chain. Also, as competition becomes fierce, many marketing strategies bring artificial fluctuation to consumer market. Diversification of products asks to further divide the market demand that heightens the uncertainty.

(6) Lack of trust. Lack of trust may cause inconsistency of decision makers. Worse still is that lack of trust creates a loop-hole for information uncertainty and latency. If the information is stuck somewhere, enterprises cannot response to emergencies in time and face the risk of greater losses.

People always pursue efficiency at the cost of the supply chain risks. But now they seem to be aware of the consequences and hope to find out its solutions. Researches on supply chain risk management are divided into quantitative ones and qualitative ones. The former studies current situation of the supply chain risks, its categories, solutions and root causes. The latter studies try to reduce risks through optimizing inventory.

Risk management of traditional supply chain aims at bullwhip effect, procurement contract design, inventory strategy, etc. However, these risk management requires that the operation be under the normal state. People often do not prepare for emergencies in advance because the possibility of happening is small. But once it happened, the losses are huge. Therefore, this sort of risk management is categorized as emergency management.

\subsection{Establishment of the emergency response capability assessment system under the emergency supply chain coordination mechanism}

We need to set up a comprehensive assessment system in order to assess the emergency response capability under the emergency supply chain coordination mechanism. The system must be objective, scientific, and reasonable. It must reflect the emergency response capability as much as possible. The system proposed by this paper is based on these principles and domestic and foreign researches. 
Table I: Emergency response capability assessment system under the emergency supply chain coordination mechanism.

\begin{tabular}{|c|c|}
\hline First level indicator & Second level indicator \\
\hline \multirow{2}{*}{ Production flexibility } & Production time flexibility \\
\hline & Production number flexibility \\
\hline \multirow{3}{*}{ Financial condition } & Turnover \\
\hline & Solvency \\
\hline & Financing \\
\hline \multirow{3}{*}{ Information sharing between enterprises } & Information sharing depth \\
\hline & Information sharing width \\
\hline & Information sharing accuracy \\
\hline \multirow{9}{*}{ Collaboration and stability } & design and development \\
\hline & Information processing \\
\hline & Production management \\
\hline & Membership stability \\
\hline & Membership synergy \\
\hline & Trust between members \\
\hline & Collaboration among members \\
\hline & Objective uniformity between members \\
\hline & Reputation among members \\
\hline \multirow{4}{*}{ Contract mechanism } & Contract incentive mechanism \\
\hline & Contract stability \\
\hline & Contract flexibility \\
\hline & Contract buffer for emergency events \\
\hline \multirow{4}{*}{$\begin{array}{c}\text { Collaborative emergency preparation } \\
\text { capability }\end{array}$} & Establishing a monitoring mechanism at all levels \\
\hline & Collaborative organization and management capacity \\
\hline & Emergency training capacity \\
\hline & Establishment of a unified emergency resources reserves \\
\hline \multirow{4}{*}{ Collaborative emergency response capability } & Information transfer capability between enterprises \\
\hline & Technical support \\
\hline & Collaboration between enterprises \\
\hline & Logistics capacity \\
\hline \multirow{5}{*}{ Rebuilding collaborative supply chain } & Unified summary and analysis between enterprises \\
\hline & Resume production \\
\hline & Repair damage \\
\hline & Emergency programs at all levels \\
\hline & Mutual collaboration between enterprises \\
\hline
\end{tabular}

\section{ASSESSMENT FRAMEWORK BASED ON HESITANT FUZZY INFORMATION}

Hesitant fuzzy information is useful to address the fuzziness and the uncertainty and this paper establishes the assessment framework based on hesitant fuzzy information.

\subsection{Generalized hesitant fuzzy distance}

Definition 1: Suppose $\alpha_{1}=\left\{h_{1}^{\sigma(1)}, h_{1}^{\sigma(2)}, \mathrm{L}, h_{1}^{\sigma(l)}\right\}$ and $\alpha_{2}=\left\{h_{2}^{\sigma(1)}, h_{2}^{\sigma(2)}, \mathrm{L}, h_{2}^{\sigma(l)}\right\}$ are any two hesitant fuzzy numbers, then the generalized hesitant fuzzy distance between $\alpha_{1}$ and $\alpha_{2}$ is defined as following:

$$
d_{g h n}\left(\alpha_{1}, \alpha_{2}\right)=\left[\frac{1}{l} \sum_{j=1}^{l}\left|h_{1}^{\sigma(j)}-h_{2}^{\sigma(j)}\right|^{\lambda}\right]^{1 / \lambda}
$$

However, two hesitant fuzzy numbers do not always have the same number of elements. Liao et al. [19] proposed a new method that equalizes the length of two sets by increasing the 
minimum element or the maximum element according to decision makers' preference. For example, let $\alpha_{1}=(0.2,0.3)$ and $\alpha_{2}=(0.1,0.3,0.5)$ be two hesitant fuzzy numbers with unequal length. If the decision maker is pessimistic, a new hesitant fuzzy number denoted as $\alpha_{1}=(0.2,0.2,0.3)$ can be acquired by adding the minimum membership in $\alpha_{1}$. Whereas if he is optimistic, we can get a new hesitant fuzzy number denoted as $\alpha_{1}=(0.2,0.3,0.3)$ by adding the maximum membership in $\alpha_{1}$.

As mentioned above, Liao et al.[19] proposed a risk neutral condition in which elements of hesitant fuzzy numbers were added to $\bar{h}=\eta h^{+}+(1-\eta) h^{-}(0 \leq \eta \leq 1)$. The new hesitant fuzzy number is denoted as $\alpha_{1}=(0.2,0.3, \bar{h})$, in which $\bar{h}=\eta 0.3+(1-\eta) 0.2$, and the parameter is dependent upon decision makers' attitude towards risks. Obviously, when $\eta=0$, it is permissive. At this moment, $\bar{h}$ is the minimum membership element. When $\eta=1$, it is optimistic. At this time, $\bar{h}$ is the maximum membership element. When $\eta=0.5$, it takes a neutral mind and $\bar{h}$ takes the average of the membership.

Definition 2: let two hesitant fuzzy sets be $M=\left\{\left\langle x, u_{M}(x)\right\rangle \mid x \in X\right\}$ and $N=\left\{\left\langle x, u_{N}(x)\right\rangle \mid x \in X\right\}$. The generalized hesitant fuzzy distance between $M$ and $N$ is defined as following:

$$
d_{g h}(M, N)=\left[\frac{1}{n} \sum_{i=1}^{n}\left(\frac{1}{l_{i}} \sum_{j=1}^{l_{i}}\left|h_{M}^{\sigma(j)}-h_{N}^{\sigma(j)}\right|^{\lambda}\right)\right]^{1 / \lambda}
$$

When $\lambda=1$, the generalized hesitant fuzzy distance reduces to Hamming distance.

When $\lambda=2$, the generalized hesitant fuzzy distance reduces to Euclidean distance.

Definition 3: Suppose that two hesitant fuzzy sets are: $M=\left\{\left\langle x, u_{M}(x)\right\rangle \mid x \in X\right\}$ and $N=\left\{\left\langle x, u_{N}(x)\right\rangle \mid x \in X\right\}$. The weighed generalized hesitant fuzzy distance between $M$ and $N$ is:

$$
d_{g h w}(M, N)=\left[\sum_{i=1}^{n} w_{i}\left(\frac{1}{l_{i}} \sum_{j=1}^{l_{i}}\left|h_{M}^{\sigma(j)}-h_{N}^{\sigma(j)}\right|^{\lambda}\right)\right]^{1 / \lambda}
$$

When $w_{i}=1 / n$, the weighed generalized hesitant fuzzy distance reduces to the generalized hesitant fuzzy distance.

Theorem 1: Suppose two hesitant fuzzy sets $M=\left\{\left\langle x, u_{M}(x)\right\rangle \mid x \in X\right\}$ and $N=\left\{\left\langle x, u_{N}(x)\right\rangle \mid x \in X\right\}$. The generalized hesitant fuzzy distance satisfies:

(1) Boundedness: $d_{g h}(M, N) \geq 0$

(2) Commutativity: $d_{g h}(M, N)=d_{g h}(N, M)$

(3) Reflexive: $d_{g h}(M, N)=0$, when $M=N$

Proof:

(1) $d_{g h}(M, N)=\left[\frac{1}{n} \sum_{i=1}^{n}\left(\frac{1}{l_{i}} \sum_{j=1}^{l_{i}}\left|h_{M}^{\sigma(j)}-h_{N}^{\sigma(j)}\right|^{\lambda}\right)\right]^{1 / \lambda}$ is known for any membership $j$,

there is $0 \leq\left|h_{M}^{\sigma(j)}-h_{N}^{\sigma(j)}\right| \leq 1$, so: $d_{g h}(M, N) \geq 0$

$$
d_{g h}(M, N)=\left[\frac{1}{n} \sum_{i=1}^{n}\left(\frac{1}{l_{i}} \sum_{j=1}^{l_{i}}\left|h_{M}^{\sigma(j)}-h_{N}^{\sigma(j)}\right|^{\lambda}\right)\right]^{1 / \lambda}=\left[\frac{1}{n} \sum_{i=1}^{n}\left(\frac{1}{l_{i}} \sum_{j=1}^{l_{i}}\left|h_{N}^{\sigma(j)}-h_{M}^{\sigma(j)}\right|^{\lambda}\right)\right]^{1 / \lambda}=d_{g h}(N, M)
$$

is known, then: $d_{g h}(M, N)=d_{g h}(N, M)$

(3) when $M=N$ :

$d_{g h}(M, N)=d_{g h}(M, M)=\left[\frac{1}{n} \sum_{i=1}^{n}\left(\frac{1}{l_{i}} \sum_{j=1}^{l_{i}}\left|h_{M}^{\sigma(j)}-h_{M}^{\sigma(j)}\right|^{\lambda}\right)\right]^{1 / \lambda}=0$

Similarly, the weighted generalized hesitant fuzzy distance is in line with the above features. 


\subsection{Improved TOPSIS method based on hesitant fuzzy information}

TOPSIS received widely attention since its initial in 1998 proposed by Hwang and Yoon. The definition of the hesitant fuzzy positive ideal solution PISA $^{+}$and the hesitant fuzzy negative ideal solution $\mathrm{PISA}^{-}$are:

$$
\begin{aligned}
& A^{+}=\left\{\alpha_{j},\langle 1\rangle_{l_{i j}}, \mid i=1, \mathrm{~K}, m ; j=1, \mathrm{~K}, n\right\} \\
& A^{-}=\left\{\alpha_{j},\langle 0\rangle_{l_{i j}} \mid i=1, \mathrm{~K}, m ; j=1, \mathrm{~K}, n\right\}
\end{aligned}
$$

This paper introduces a weighed generalized hesitant fuzzy distance to measure the distance of an alternative to the positive ideal solution $d_{i}^{+}$and that to the negative ideal solution $d_{i}^{-}$. The definition is:

$$
\begin{gathered}
d_{i}^{+}=\left[\sum_{j=1}^{n} w_{j}\left(\frac{1}{l_{i j}} \sum_{p=1}^{l_{i j}}\left|h_{i j}^{\sigma(p)}-1\right|^{\lambda}\right)\right]^{1 / \lambda} \\
d_{i}^{-}=\left[\sum_{j=1}^{n} w_{j}\left(\frac{1}{l_{i j}} \sum_{p=1}^{l_{i j}}\left|h_{i j}^{\sigma(p)}\right|^{\lambda}\right)\right]^{1 / \lambda}
\end{gathered}
$$

In traditional TOPSIS, the closeness coefficient of any alternative is defined as:

$$
C_{i}=\frac{d_{i}^{-}}{d_{i}^{+}+d_{i}^{-}}
$$

Based on the satisfaction of the alternative of Liao et al. [19], this paper proposes a closeness coefficient of improved TOPSIS:

$$
C C_{i}=\frac{(1-\theta) d_{i}^{-}}{\theta d_{i}^{+}+(1-\theta) d_{i}^{-}}
$$

Parameter $\theta$ refers to decision makers' attitude towards risks. It fits $0<\theta<1$. When $\theta>0.5$, it is permissive. When $\theta<0.5$, it is optimistic and likely to take a risk. And when $\eta=0.5$, it takes a neutral mind. In particular, when $\theta=1$, it is absolutely permissive and $C C_{i}=d_{i}^{+}$. But there is no such thing as absolute pessimist or absolute optimist. So, taking the closeness coefficient of decision makers' attitude towards risks is more in line with the situation than without such consideration. It is easier to get a satisfied assessment result.

\subsection{Assessment framework and steps}

The assessment framework based on hesitant fuzzy information is as Fig. 2.

Here are the assessment steps based on TOPSIS:

Step 1: Let $A=\left\{A_{1}, A_{2}, \mathrm{~L}, A_{m}\right\}$ be a discrete set of alternatives, $C=\left\{C_{1}, C_{2}, \mathrm{~L}, C_{n}\right\}$ be a collection of attributes. The assessment value $\tilde{\alpha}_{i j}(i=1,2, \ldots, m ; j=1,2, \ldots, n)$ of the alternative $A_{i}$ under attribute $C_{j}$ is expressed as the hesitant fuzzy number. Then, we can construct the decision matrix of hesitant fuzzy number as follows:

$$
D=\left(\begin{array}{cccc}
\tilde{\alpha}_{11} & \tilde{\alpha}_{12} & \cdots & \tilde{\alpha}_{1 n} \\
\tilde{\alpha}_{21} & \tilde{\alpha}_{22} & \cdots & \tilde{\alpha}_{2 n} \\
\vdots & \vdots & \ddots & \vdots \\
\tilde{\alpha}_{m 1} & \tilde{\alpha}_{m 2} & \cdots & \tilde{\alpha}_{m n}
\end{array}\right)
$$

Step 2: $\quad$ Confirm the attribute weight in set $C$.

Step 3: Confirm the positive ideal solution and the negative ideal solution of the assessment alternative.

Step 4: According to the weighed generalized hesitant fuzzy distance, calculate the distance of each alternative $a_{i} \in A$ to the positive ideal solution and that to the negative ideal 
solution.

Step 5: Calculate the closeness coefficient of each assessment alternative $a_{i} \in A$.

Step 6: According to the closeness coefficient of each assessment alternative to the ranking, the larger the coefficient is, the better the assessment alternative is.

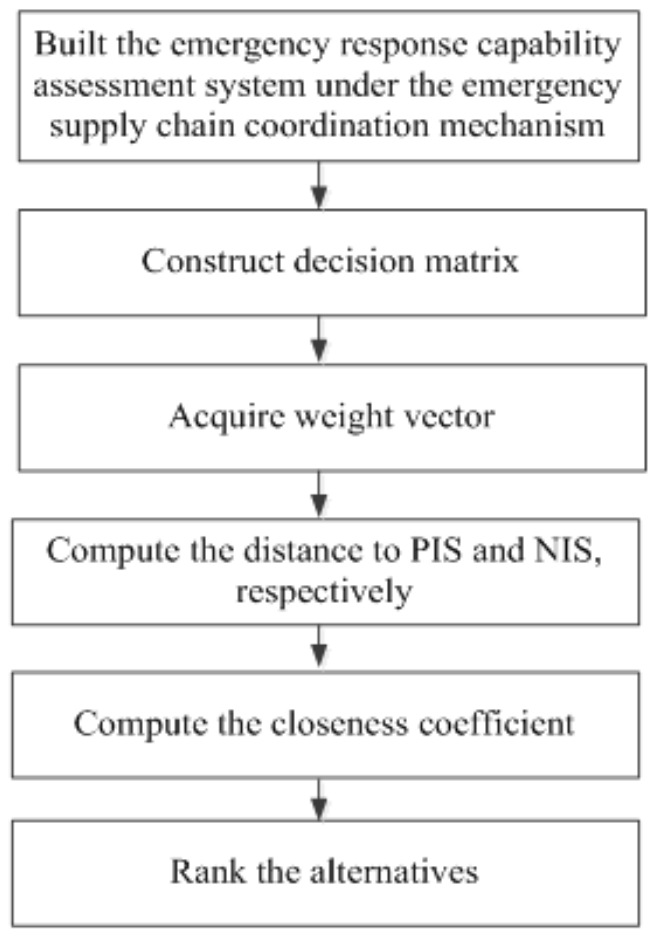

Figure 2: Assessment framework of hesitant fuzzy information.

\section{THE SIMULATION OF ASSESSMENT ISSUE}

This paper selected five related companies for the assessment, namely, $A=\left\{A_{1}, A_{2}, \ldots, A_{5}\right\}$. First level indicators which have eight indicators in Table II are the rating attribute set, namely, $C=\left\{C_{1}, C_{2}, \ldots, C_{8}\right\}$. Second level indicators are reference index given by experts. The project manager takes the role of decision-maker who invited three experts to give weight of the decision attribute. The weight vector $w=\left(w_{1}, w_{2}, \ldots, w_{n}\right)$, which meets $w_{j} \in[0,1](j=1$, $2, \ldots, n), \sum_{j=1}^{n} w_{j}=1$. The decision maker estimates that his attitude towards the risk assessment is neutral conservative expressed by a hesitant fuzzy number as $\theta_{s}=\{0.2,0.3,0.5\}$. Use hesitant fuzzy number to assess each alternative and get the original decision matrix $A=\left(h_{i j}\right)_{5 \times 8}$. Normalize the matrix according to decision maker's attitude towards risks (in this paper, it is $\eta=0.5$ ), as shown in Table II. As space is limited, the original matrix is not listed.

According to the generalized fuzzy weighted distance, calculate the distance of each alternative to hesitant fuzzy positive ideal solution and hesitant fuzzy negative ideal solution under parameter $\lambda$.

In Fig. 3 (left and right), the distance of the alternative to the positive ideal solution under different parameter $\lambda$ is not the same as that to the negative ideal solution. When $\lambda=2$, the variation of five alternatives is different under other situations. In Fig. 4 , when $\lambda=4,6,8$, the curve fitting is almost the same. Here concludes that if the parameter $\lambda$ increases, the curve will overlap to each other.

After the distance is acquired, we can calculate the closeness coefficient of each alternative and the ranking of them under different decision makers' attitude towards risks. 
Table II: Normalized decision matrix $A$.

\begin{tabular}{|l|c|c|c|c|c|}
\hline & $\boldsymbol{A}_{\mathbf{1}}$ & $\boldsymbol{A}_{\mathbf{2}}$ & $\boldsymbol{A}_{\mathbf{3}}$ & $\boldsymbol{A}_{\mathbf{4}}$ & $\boldsymbol{A}_{\mathbf{5}}$ \\
\hline $\boldsymbol{C}_{\mathbf{1}}$ & $\{0.7,0.75,0.8\}$ & $\{0.3,0.4,0.5\}$ & $\{0.4,0.45,0.5\}$ & $\{0.2,0.3,0.4\}$ & $\{0.6,0.65,0.7\}$ \\
\hline $\boldsymbol{C}_{\mathbf{2}}$ & $\{0.6,0.7,0.8\}$ & $\{0.4,0.5,0.6\}$ & $\{0.1,0.25,0.4\}$ & $\{0.3,0.4,0.5\}$ & $\{0.5,0.6,0.7\}$ \\
\hline $\boldsymbol{C}_{\mathbf{3}}$ & $\{0.6,0.7,0.8\}$ & $\{0.2,0.25,0.3\}$ & $\{0.1,0.2,0.3\}$ & $\{0.4,0.5,0.6\}$ & $\{0.6,0.65,0.7\}$ \\
\hline $\boldsymbol{C}_{\mathbf{4}}$ & $\{0.5,0.6,0.8\}$ & $\{0.4,0.5,0.6\}$ & $\{0.2,0.3,0.4\}$ & $\{0.3,0.4,0.5\}$ & $\{0.7,0.8,0.9\}$ \\
\hline $\boldsymbol{C}_{\mathbf{5}}$ & $\{0.6,0.7,0.8\}$ & $\{0.3,0.4,0.5\}$ & $\{0.2,0.25,0.3\}$ & $\{0.4,0.45,0.5\}$ & $\{0.7,0.75,0.8\}$ \\
\hline $\boldsymbol{C}_{\mathbf{6}}$ & $\{0.3,0.4,0.5\}$ & $\{0.3,0.4,0.5\}$ & $\{0.2,0.25,0.3\}$ & $\{0.4,0.5,0.6\}$ & $\{0.5,0.55,0.6\}$ \\
\hline $\boldsymbol{C}_{\mathbf{7}}$ & $\{0.6,0.7,0.8\}$ & $\{0.1,0.2,0.3\}$ & $\{0.3,0.4,0.5\}$ & $\{0.2,0.3,0.4\}$ & $\{0.7,0.75,0.8\}$ \\
\hline $\boldsymbol{C}_{\mathbf{8}}$ & $\{0.1,0.2,0.3\}$ & $\{0.4,0.45,0.5\}$ & $\{0.6,0.65,0.7\}$ & $\{0.5,0.55,0.6\}$ & $\{0.1,0.2,0.3\}$ \\
\hline
\end{tabular}
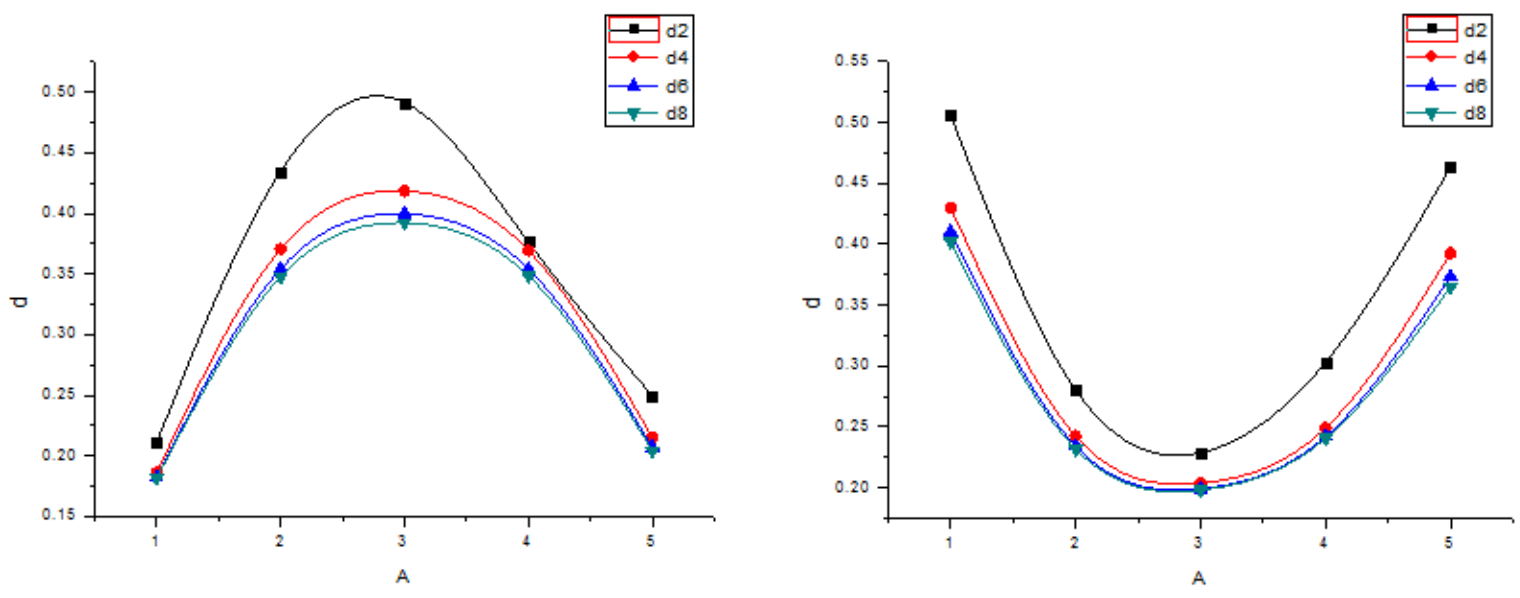

Figure 3: Distance of each alternative to positive (left) and negative (right) ideal solution under different distance formula.

From Figs. 4 to 5 we can see under different decision makers' preference the curve of the Closeness coefficient of the alternative has the same trend of variation. In this study, the ranking of the alternative is consistent. In other words, decision makers have limited influence over the results.
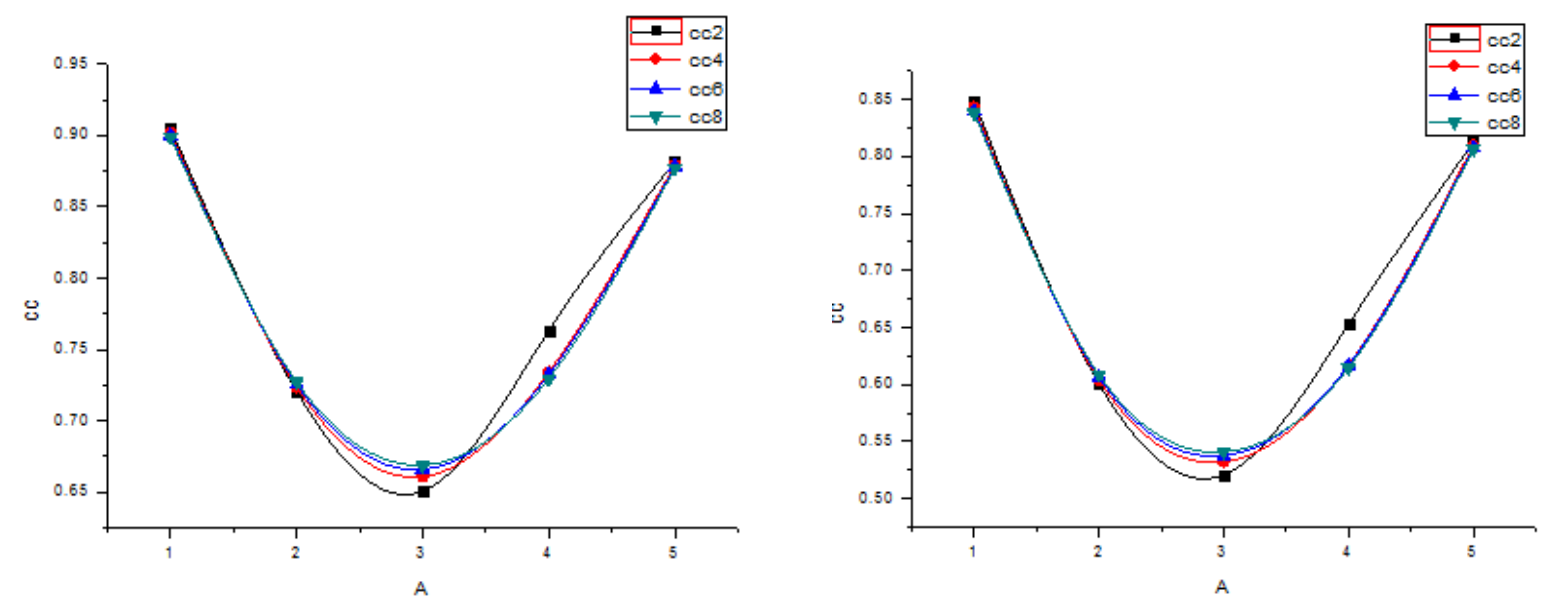

Figure 4: Closeness coefficient of the alternative under parameter $\lambda$ at $\theta=0.2$ and at $\theta=0.3$.

As can be seen from Figs. 6 to 7, the ranking of different alternatives under different parameters doesn't change. Rather, the variation takes on the same trend. But the trend of increment is inconsistent with the decreasing trend. This finding fits Liao's [19] research in 
the movie recommendation system for decision-making research. In Liao's study, the ranking under different parameters is not entirely consistent, that is to say, if the value given by experts has changed, the ranking will change as well, in particular when the assessment value of two alternatives are close to each other. However, in this paper, the ranking is consistent, which means the result is robust. Therefore, we can say with certainty that Enterprise $A_{1}$ is the selected enterprise to cooperate with.

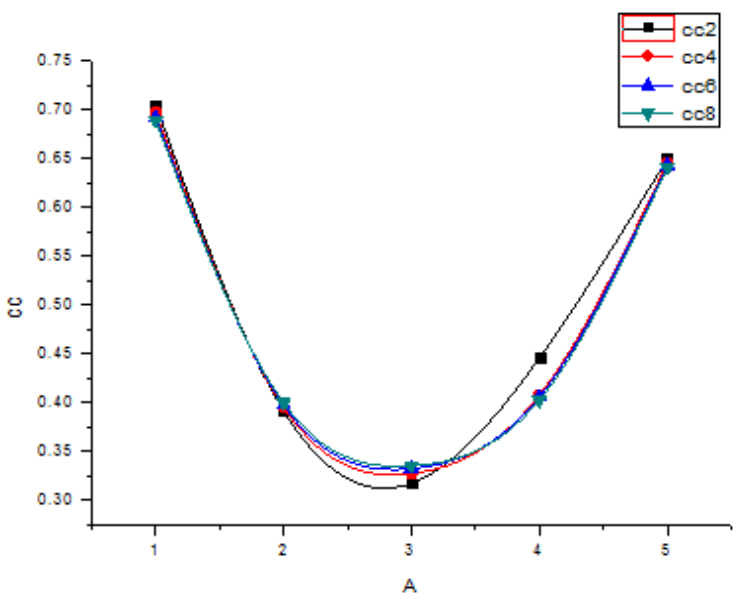

Figure 5: Closeness coefficient of the alternative under parameter $\lambda$ at $\theta=0.5$.
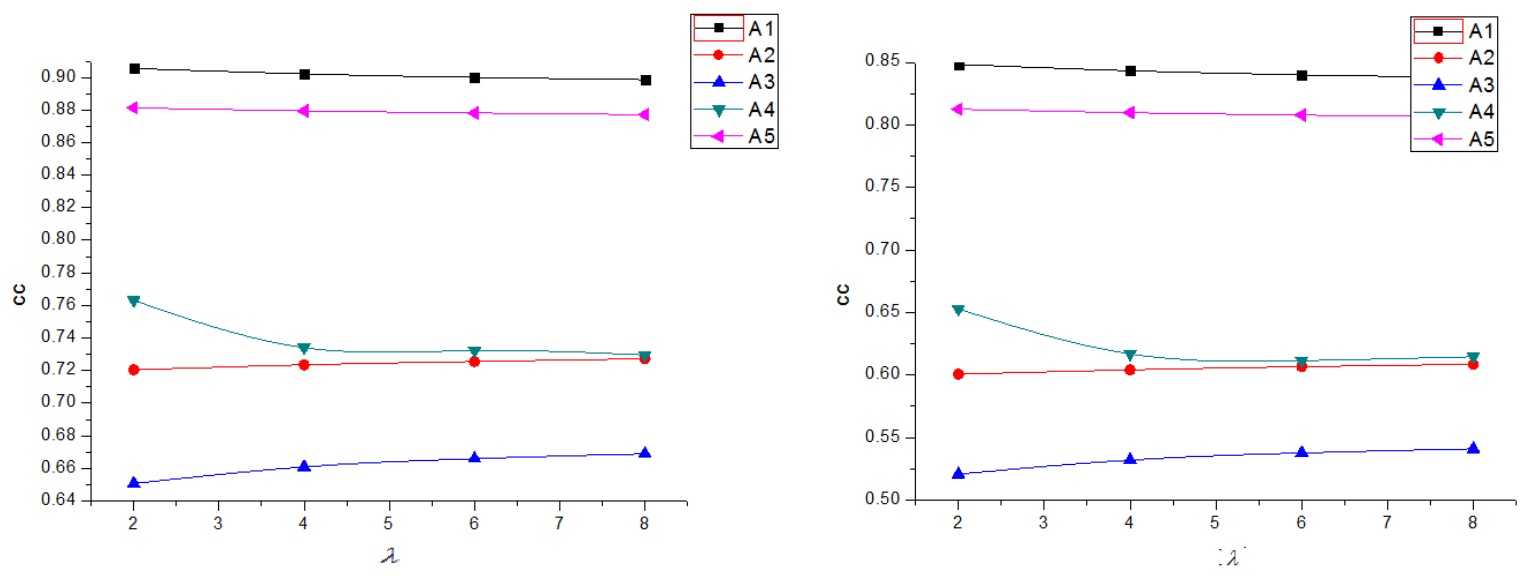

Figure 6: Closeness coefficient of the alternative under parameter $\lambda$ at $\theta=0.2$ and at $\theta=0.3$.

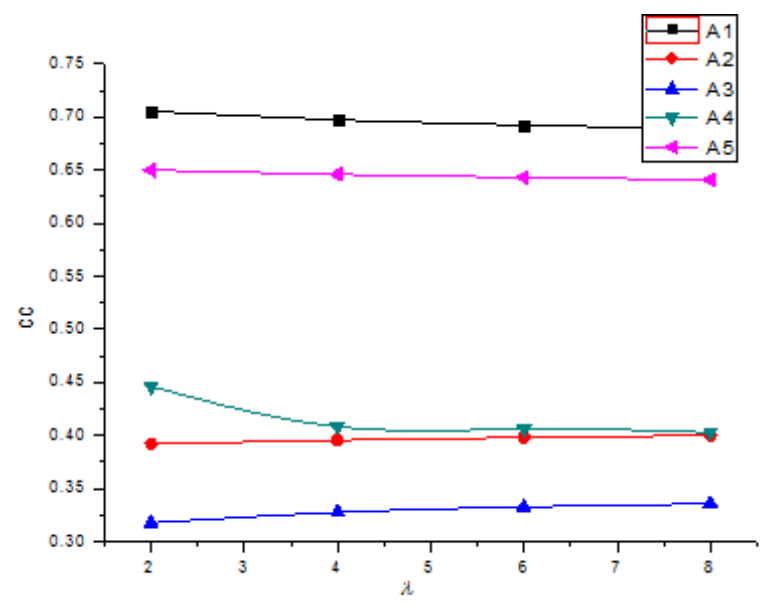

Figure 7: Closeness coefficient of the alternative under parameter $\lambda$ at $\theta=0.5$. 


\section{CONCLUSION}

As global economy is intertwined, enterprises take on agile supply chain strategy. Though this strategy reduces costs and adds profits, it makes the supply chain more vulnerable than ever before. Once there are emergencies, huge losses would take its toll. Coordination mechanism is one of the important strategies in response to supply chain risks. In the face of emergencies, coordinating companies at all nodes through coordination mechanism and constraining individual purpose for the benefits of all are just useful ways of supply chain management. Therefore, it is significant to study the emergency response capability assessment under the emergency supply chain coordination mechanism.

This paper is creative in the following aspects: (1) It constructs a comprehensive emergency response capability assessment system under the emergency supply chain coordination mechanism through a careful study of domestic and foreign theories. (2) It introduces the generalized hesitant fuzzy distance to TOPSIS, takes into account the preference of decision makers and proposes the TOPSIS METHOD based on hesitant fuzzy information. (3) It applies TOPSIS METHOD to the assessment of emergency response capability and carries out the simulation and the analysis of parameters. Finally, the experiment proves that this method has efficacy.

\section{ACKNOWLEDGEMENTS}

This research was supported by the Humanities and Social Science Project of Chinese Ministry of Education (NO.13YJC630015), the Heilongjiang Natural Science Foundation (NO.F201341), National Natural Science Foundation of China (NO.71101034), the Heilongjiang Postdoctoral Science Research Foundation (NO.LBH-Q12123) and the Fundamental Research Funds for the Chinese Universities (NO.HEUCF140902).

\section{REFERENCES}

[1] Clausen, J.; Hansen, J.; Larsen, J.; Larsen, A. (2001). Disruption management, OR/MS Today, Vol. 28, No. 5, 40-43

[2] Lei, Z. (2008). Study on the relationship between the supply chain security and its cost, Huazhong University of Science and Technology, Management Science and Engineering

[3] Zhu, L. (2012). Emergency management mechanism modeling and application of supply chainCase study of Mengniu group, Ocean University of China, Management Science and Engineering

[4] Li, L. H. (2012). Assessment of supply chain emergency capability based on the analytic hierarchy process (AHP) and fuzzy comprehensive assessment method, Shandong University of Finance and Economics, Management Science and Engineering

[5] Xiao, T.; Yu, G. (2006). Supply chain disruption management and evolutionarily stable strategies of retailers in the quantity-setting duopoly situation with homogeneous goods, European Journal of Operational Research, Vol. 173, No. 2, 648-668, doi:10.1016/j.ejor.2005.02.076

[6] Tomlin, B. T. (2005). Selecting a disruption-management strategy for short life-cycle products: diversification, contingent sourcing, and demand management (Working Paper), Kenan-Flagler Business School, University of North Carolina

[7] Tomlin, B.; Wang, Y. (2005). On the value of mix flexibility and dual sourcing in unreliable newsvendor networks, Manufacturing \& Service Operations Management, Vol. 7, No. 1. 37-57, doi: $10.1287 / \mathrm{msom} .1040 .0063$

[8] Deng, L. (2012). Supply chain aid in emergency collaborative emergency problem, Chongqing University, Economics and Business Administration

[9] Nosoohi, I.; Nookabadi, A. S. (2014). Designing a supply contract to coordinate supplier's production, considering customer oriented production, Computers \& Industrial Engineering, Vol. 74, 26-36, doi:10.1016/j.cie.2014.04.012 
[10] Luo, J.-W.; Zhang, Q.-H. (2012). Trade credit: A new mechanism to coordinate supply chain, Operations Research Letters, Vol. 40, No. 5, 378-384, doi:10.1016/j.orl.2012.04.008

[11] Hwang, C. L.; Yoon, K. (1981). Multiple attribute decision making: methods and applications, Springer Verlag, Berlin

[12] Bilbao-Terol, A.; Arenas-Parra, M.; Canal-Fernandez, V.; Antomil-Ibias, J. (2014). Using TOPSIS for assessing the sustainability of government bond funds, Omega, Vol. 49, 1-17, doi:10.1016/j.omega.2014.04.005

[13] Wang, Y.-J. (2014). The evaluation of financial performance for Taiwan container shipping companies by fuzzy TOPSIS, Applied Soft Computing, Vol. 22, 28-35, doi:10.1016/j.asoc.2014.03.021

[14] Zhu, X.-Q.; Wang, F.; Liang, C.-Z.; Li, J.-P.; Sun, X.-L. (2012). Quality credit evaluation based on TOPSIS: Evidence from air-conditioning market in China, Procedia Computer Science, Vol. 9, 1256-1262, doi:10.1016/j.procs.2012.04.137

[15] Dubois, D.; Prade, H. (1980). Fuzzy sets and systems: Theory and applications, Academic Press, New York

[16] Atanassov, K. T. (1986). Intuitionistic fuzzy sets, Fuzzy Sets and Systems, Vol. 20, No. 1, 87-96, doi:10.1016/S0165-0114(86)80034-3

[17] Torra, V. (2010). Hesitant fuzzy sets, International Journal of Intelligent Systems, Vol. 25, No. 6, 529-539, doi:10.1002/int.20418

[18] Torra, V.; Narukawa, Y. (2009). On hesitant fuzzy sets and decision, The $18^{\text {th }}$ IEEE International Conference on Fuzzy Systems, Jeju Island, Korea, 1378-1382

[19] Liao, H.-C.; Xu, Z.-S.; Zeng. X.-J. (2014). Distance and similarity measures for hesitant fuzzy linguistic term sets and their application in multi-criteria decision making, Information Sciences, Vol. 271, 125-142, doi:10.1016/j.ins.2014.02.125 